UDK: 624.012.4.059

DOI: https://doi.org/10.24867/02CG02Bukvic

\title{
PROCENA STANjA, SANACIJA AB KONSTRUKCIJE I REKONSTRUKCIJA STUDIJA U SUTERENU STARE ZGRADE RADIO-TELEVIZIJE VOJVODINE
}

\section{ASSESSMENT, REPAIR OF RC STRUCTURES AND RECONSTRUCTION OF STUDIES IN THE BASEMENT OF THE OLD BUILDING OF RADIO-TELEVISION VOJVODINA}

Olivera Bukvić, Fakultet tehničkih nauka, Novi Sad

\section{Oblast - GRAĐEVINARSTVO}

Kratak sadržaj - U radu je prikazana procena stanja $i$ sanacija armiranobetonske konstrukcije dela suterena stare zgrade Radio-televizije Vojvodine. $\mathrm{Na}$ osnovu rezultata detaljnog vizuelnog pregleda konstrukcije, dato je sanaciono rešenje u skladu sa namenom objekta.

Ključne reči: Procena stanja, Sanacija konstrukcija, Armiranobetonske konstrukcije

Abstract - This paper presents assessment and repair of reinforced structure, which was part of basement in the old building complex of Radio-Television of Vojvodina. Based on the results of visual examination, repair project was made, in accordance with purpose of structure.

Keywords: Assessment, Repair of structures, Reinforced concrete structures

\section{TEORIJSKO ISTRAŽIVAČKI DEO}

Pored svih konstrukcijskih zahteva koje objekat mora da ispuni, objekti namenjeni boravku ljudi moraju da zadovolje posebne zahteve vezane za nivo buke i akustiku. Akustički kvalitet nekog građevinskog objekta određen je akustičkim komforom čoveka.

Ovaj pojam podrazumeva zadovoljenost skupa elemenata akustičkog kvaliteta koji utiču na ugodnost boravka [1]. Zvučne karakteristike neke prostorije zavisiće od njenih geometrijskih karakteristika, ali i od upotrebljenih izolacionih materijala.

\subsection{Oblici zvuka u građevinskim konstrukcijama}

Zvuk predstavlja svaku vremenski promenljivu deformaciju u elastičnoj sredini [2]. Prostire se kroz čvrsta tela ili fluide i po svojoj prirodi je talasno kretanje.

U građevinskim konstrukcijama pojavljuje se kao vazdušni i strukturni zvuk, u zavisnosti od toga kroz koju sredinu se kreće. Kretanje strukturnog zvuka je složenije i zavisi od karakteristika materijala kroz koji prolazi. Zbog toga je od velike važnosti sagledati put zvuka kroz konstrukciju prilikom njenog projektovanja [1,3]. Slika 1 prikazuje šemu puteva zvuka između dve prostorije.

\section{NAPOMENA:}

Ovaj rad proistekao je iz master rada čiji mentor je bila dr Mirjana Malešev, red. prof.

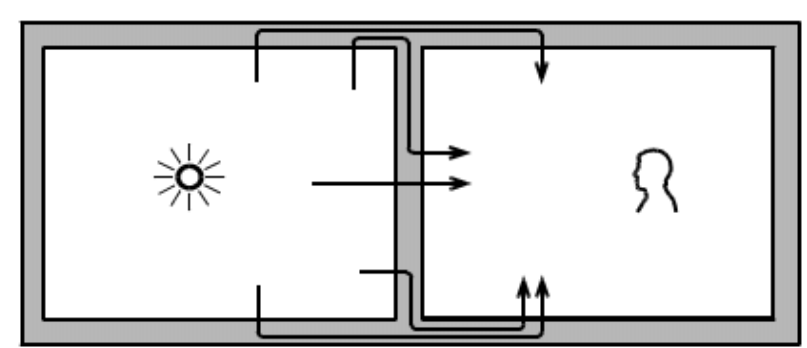

Slika 1. Šema provođenja zvuka [1]

\subsection{Principi zaštite od strukturnog zvuka}

Ovakva vrsta pobude u konstrukciji može nastati lokalno na mestima rada obrtnih mašina, ili može biti raspoređena, kada se javlja svuda gde su moguće ljudske aktivnosti [2]. Lokalna pobuda u konstrukcijskom materijalu može se efikasno izolovati samo ako se apsorpcioni sistemi nalaze na mestu nastanka zvuka. Ovakvi apsorpcioni sistemi su mehanički filteri (sika 2).

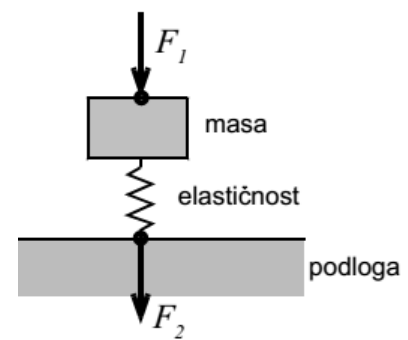

Slika 2. Princip rada mehaničkog filtera [1]

Sistem čine masa i elastična opruga. Veličina mase i krutost opruge određuju rezonantnu frekvenciju sistema. Ako je frekvencija pobude (zvuka) niža od rezonantne frekvencije, sila $F_{2}$ će biti jednaka sili $F_{1}$, odnosno, zvuk će se preneti na sistem koji je trebalo izolovati. Za frekvencije filtera niže od frekvencija pobude, moguće je smanjiti intenzitet sile $F_{1}[1,3]$. Niža frekvencija opruge znači njenu manju krutost, odnosno sposobnost da se deformiše usled sile $F_{1}$, koja na taj način „troši“ više energije zvuka, odnosno on se u manjoj meri prenosi na donju podlogu. Zbog toga je pogodno birati materijale, za ulogu elastične opruge, koji osciluju na nižim frekvencijama.

$\mathrm{Na}$ tržištu postoji veliki broj različitih materijala za izradu elastičnih oslonaca. To mogu biti sistemi na bazi gume ili čeličnih opruga [1]. U zavisnosti od toga kolika masa stvara pobudu, bira se i krutost opruge.

Površinski raspoređena pobuda se izoluje izvođenjem drugačijih filtera - plivajućih podova (slika 3 ). 


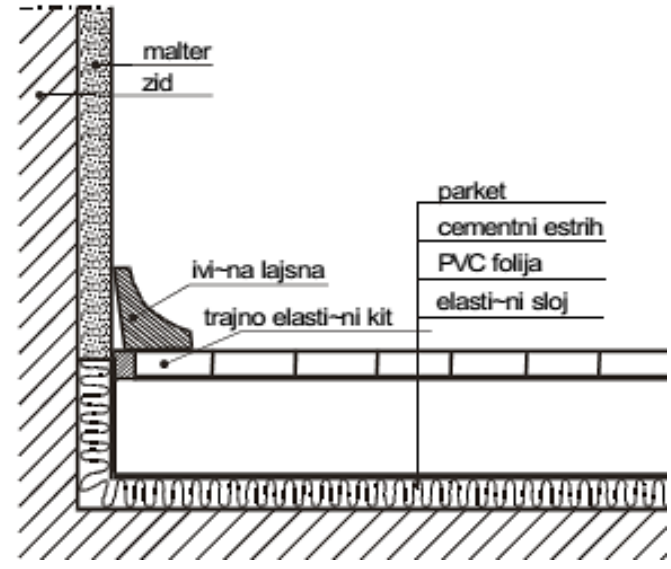

Slika 3. Plivajući pod [1]

Efikasnost ovih sistema zavisi od materijala koji ima ulogu elastične opruge - kruti (tvrdi) materijali imaće visoku rezonantnu frekvenciju, usled čega će efikasnost zvučne izolacije biti smanjena [1].

\section{PROCENA STANJA AB KONSTRUKCIJE}

Kompleks Javne medijske ustanove „Radio-televizije Vojvodine" nalazi se na katastarskoj parceli 2701 K.O. u Petrovaradinu. Objekti na predmetnoj parceli, namenjeni produkciji, obradi i emitovanju programa RTV, izgrađeni su tokom sedamdesetih i osamdesetih godina prošlog veka. Kompleks je srušen za vreme NATO bombardovanja 1999. godine. Preostali deo objekta je porušen, a suterenski deo je predviđen za sanaciju. Predmet ovog rada je sanacija delova Studio 1 i Studio 2 (Slika 4).

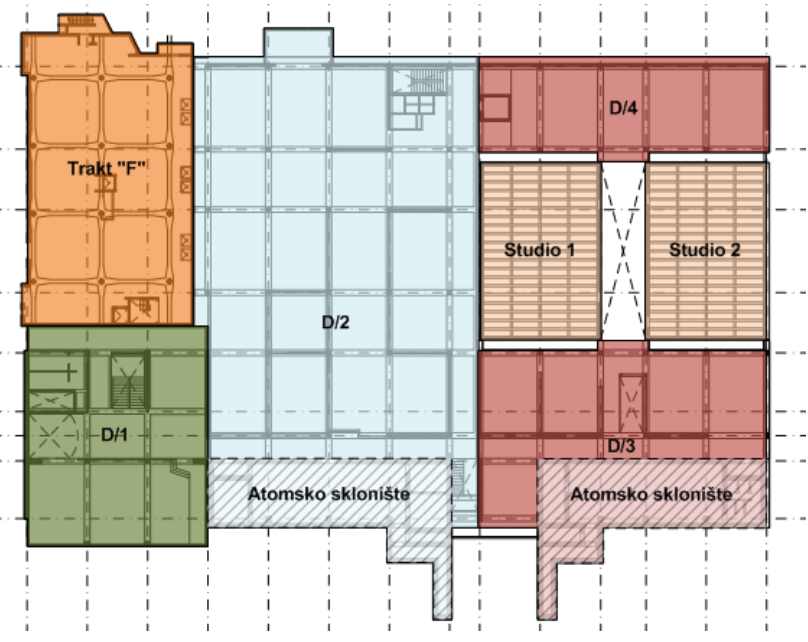

Slika 4. Položaj studija u odnosu na suteren

\subsection{Opis konstrukcije Studija 1 i Studija 2}

Analizom projektne dokumentacije utvrđeno je da je konstruktivni sistem delova suterena „Studio $1^{\text {“ }} \mathrm{i}$,Studio 2“ projektovan kao masivni, sa nosećim $\mathrm{AB}$ zidovima $\mathrm{i}$ monolitnom rebrastom tavanicom (rebra $20 / 60 \mathrm{~cm}$ i ploča $\mathrm{dp}=10 \mathrm{~cm})$. U podužnom pravcu projektovana su tri rebra za ukrućenje, istih dimenzija kao i glavna rebra, postavljena u četvrtinama raspona. Predviđeno je proširenje preseka glavnih rebara nad osloncima. Projektovana marka betona za međuspratnu konstrukciju je MB40. AB zidovi su debljine $30 \mathrm{~cm}$, visine $5,0 \mathrm{~m}$. Projektovana marka betona je MB30. Vizuelnim pregledom konstruk- cije i terenskim ispitivanjima utvrđeno je da se izvedeno stanje delimično razlikuje od projektovanog. Navedena proširenja nisu izvedena i nije postignut zajednički rad glavnih rebara i ploče. Ovo je uticalo na drugačije ponašanje konstrukcije od projektovanog.

\subsection{Karakteristični defekti i oštećenja}

U Studiju 1 i Studiju 2 (slika 5) pregledani su elementi međuspratne konstrukcije - ploča i rebra, i obodni zidovi.

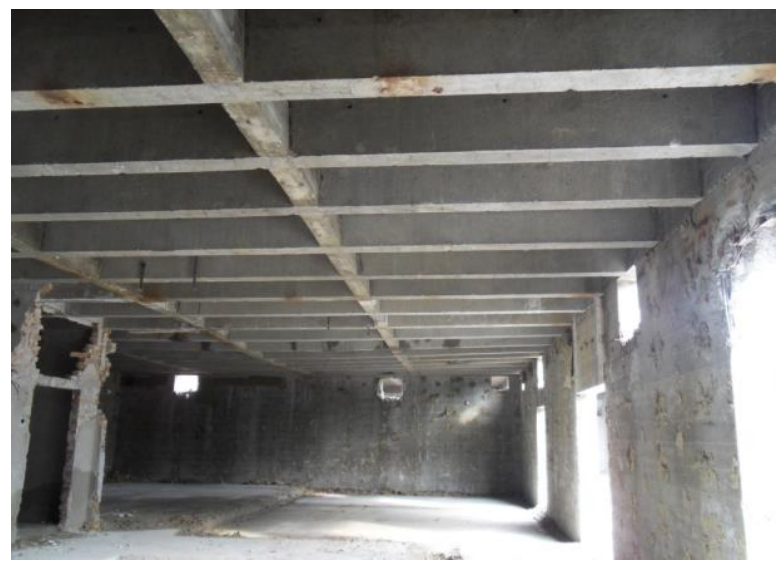

Slika 5. Izgled konstrukcije

Karakterističan defekat svih elemenata je mala debljina zaštitnog sloja betona i vidljiva armatura, prikazana na slici 6.

Dominantna oštećenja glavnih rebara su prsline i pukotine usled savijanja (slika 7) i smicanja. Veliki registrovani ugibi rebara su posledica preopterećenja i odstupanja od projekta prilikom izvođenja.

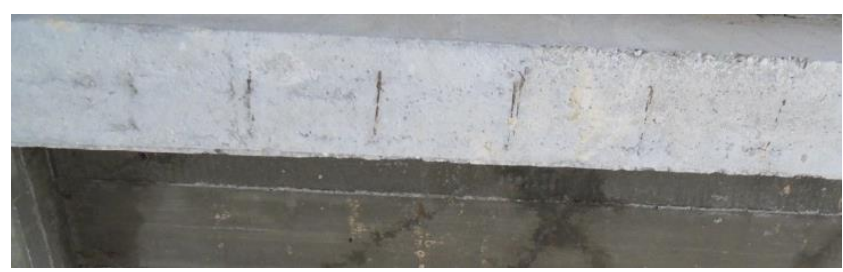

Slika 6. Nedovoljna debljina zaštitnog sloja betona $i$ vidljive uzengije grede

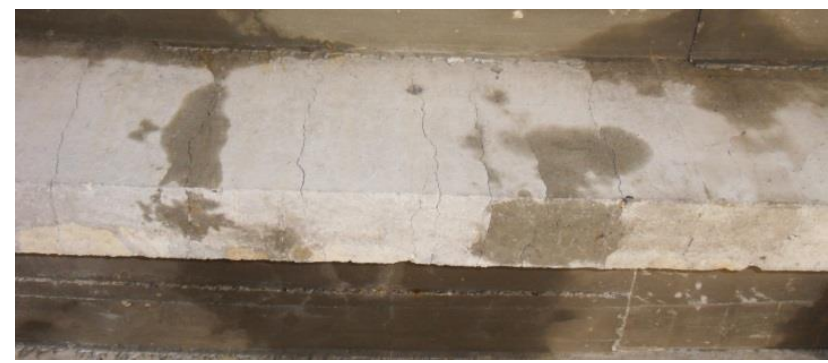

Slika 7. Prsline usled savijanja grede

Korozija armature, procurivanje vode i prsline usled preopterećenja, karakteristične su za ploču. Na slici 8, prikazan je jedan od najoštećenijih delova ploče, a na slici 9 mehaničko oštećenje rebra.

Procurivanje vode na spojevima elemenata i kroz prsline primećeno je i na pločama i na gredama. 


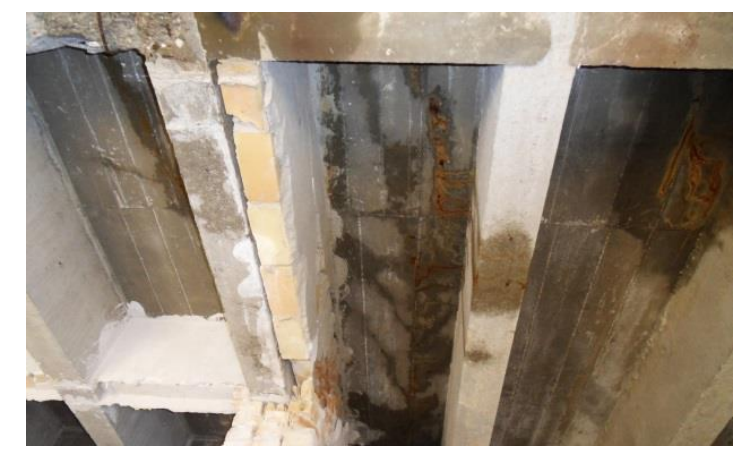

Slika 8. Oštećenja ploče

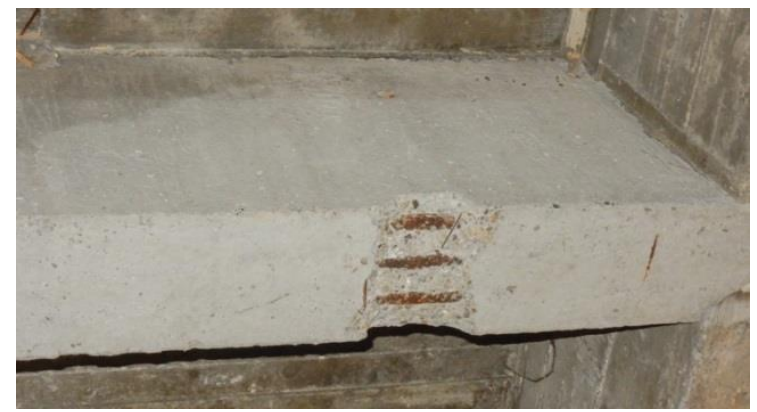

Slika 9. Mehaničko ođtećenje rebra i vidljiva armatura

Pored navedenih defekata, na zidovima su registrovani i nepravilni prekidi betoniranja, a od oštećenja prsline usled dugotrajnog hidrauličnog skupljanja. Kao posledica bombardovanja, prisutna su i mehanička oštećenja. Izgled tipičnog obodnog zida studija prikazan je na slici 10 .

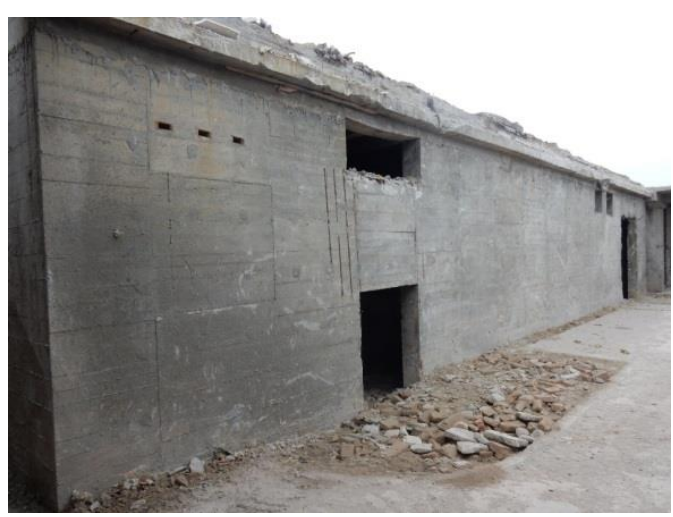

Slika 10. Obodni zid studija

\subsection{Zaključak o stanju konstrukcije}

$\mathrm{Na}$ osnovu analize stanja rebraste polumontažne međuspratne konstrukcije, zaključeno je da je nosivost međuspratne konstrukcije značajno smanjena, a stabilnost ugrožena na polovini površine ploče Studija 1. Nosivost međuspratne konstrukcije Studija 2 je lokalno smanjena Zbog prodora vode kroz prsline i pukotine u pločama, kao i zbog direktne izloženosti spoljašnjim uticajima, trajnost elemenata međuspratne AB konstrukcije je delimično smanjena $\mathrm{i}$ ako se ne preduzmu mere na sprečavanju prodora vode i zatvaranju objekta trajnost konstrukcije će u kratkom vremenskom periodu biti značajno ugrožena. Nosivost zidova je očuvana, osim na zidu u osi C, lokalno.

\subsection{Sanacija konstrukcije}

Sanaciono rešenje predviđa uklanjanje ploče sa oba studija i uklanjanje polovine glavnih rebara Studija 1 (Slika 11).

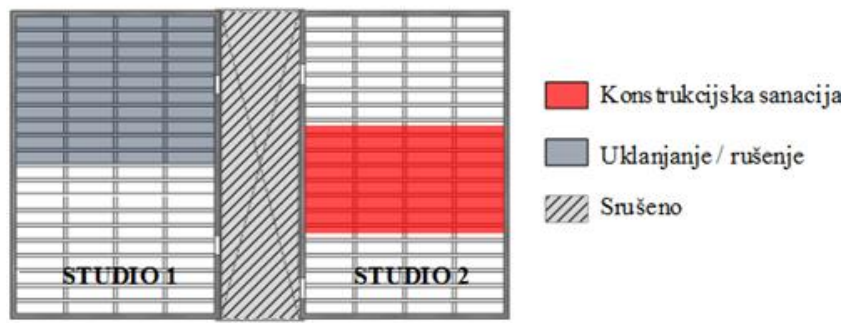

Slika 11. Šematski prikaz uklanjanja $M K$

Usled velikih ugiba rebara, potrebno je promeniti njihov statički sistem, što se postiže izvođenjem čeličnog rama ispod njih. Betoniranje ploče i glavnih rebara izvodiće se tako da se ostvari njihov zajednički rad. Ovo se postiže zavarivanjem dodatnih uzengija rebara i njihovim ispuštanjem. Namena objekata je muzički studio, sa intenzivnim zelenim krovom na krovnoj ploči. U skladu sa ovim zahtevima, sprovedena je anaiza opterećenja i modeliranje konstrukcije u softverskom paketu Tower 7 . Na slici 12 prikazan je 3D model jednog studija.

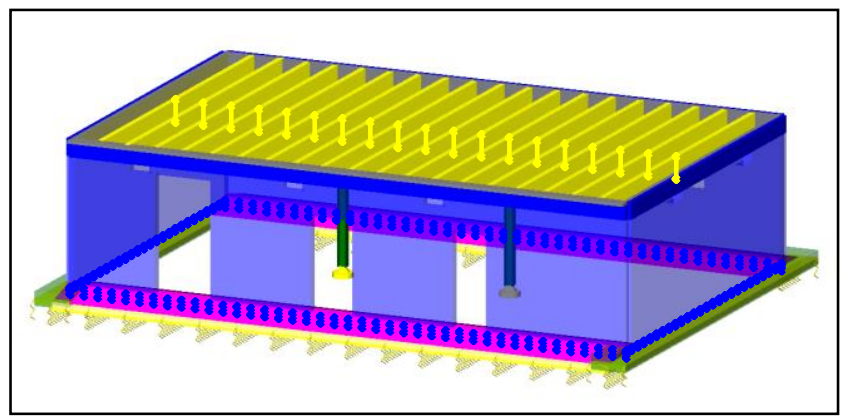

Slika 12. Prostornimodel konstrukcije

U nastavku je dat spisak aktivnosti potrebnih za izvođenje sanacije:

1. Uklanjanje dela postojećih temelja;

2. Betoniranje temelja samaca za stubove čeličnog rama;

3. Montaža čeličnog rama;

4. Betoniranje podne ploče;

5. Podupiranje međuspratne konstrukcije;

6. Uklanjanje ploče međuspratne konstrukcije;

7. Uklanjanje dela glavnih rebara Studija 1;

8. Postavljanje dodatne poprečne armature glavnih rebara;

9. Injektiranje prslina i pukotina glavnih i podužnih rebara i zidova (Studio 1 i 2);

10. Betoniranje zidova, rebara i ploča (Studio 1 i 2).

Uklanjanje međuspratne ploče izvodiće se presecanjem ploče između rebara, hidrauličkim makazama i odnošenjem na deponiju pomoću dizalice. Šema isecanja ploče prikazana je na slici 13 . 


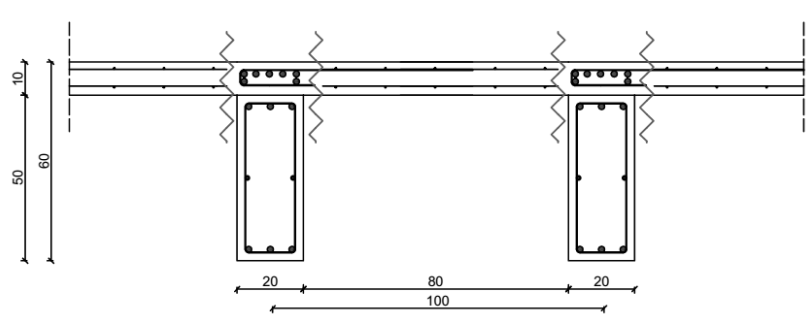

Slika 13. Uklanjanje ploče međuspratne konstrukcije

Nakon uklanjanja ploče, injektiraju se prsline glavnih rebara i rebara za ukrućenje veće od $0,3 \mathrm{~mm}$.

Pre postavljanja dodatne armature, potrebno je profometrom odrediti položaj uzengija rebara. Nakon toga se razbija oko $10 \mathrm{~cm}$ betona sa jedne strane svake uzengije, ručnim čekićem. Na tom mestu se, u podužnom pravcu rebra vari nova šipka, istog prečnika kao postojeća. Predviđen je bočni var, dužine $10 \mathrm{~cm}$.

Kroz novopostavljene uzengije provlači se armatura i oplata greda i ploča usvojena prilikom dimenzionisanja. Zatim se ovi elementi betoniraju mešavinom odgovarajuće konzistencije i sastava. Plan armiranja jednog rebra i ploče, prikazan je na slici 14 .

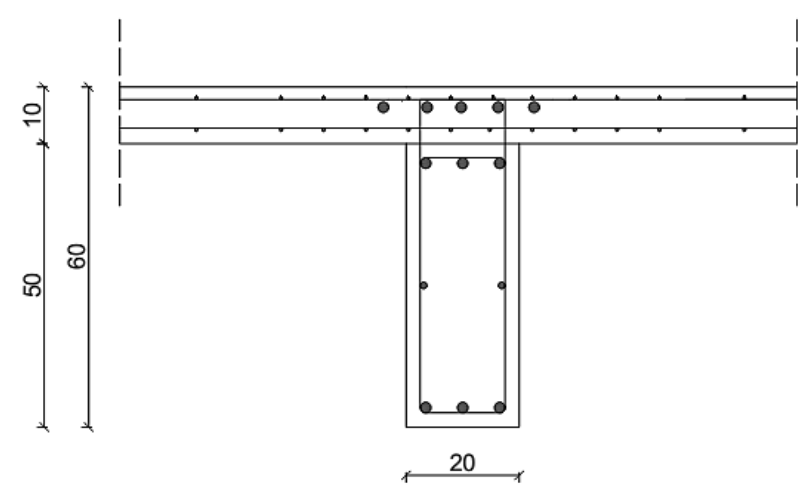

Slika 14. Armiranje saniranog preseka

\section{ZAKLJUČAK}

U cilju daljeg korišćenja objekta sprovedena je konstrukcijska i nekonstrukcijska sanacija armiranobetonske konstrukcije dela suterena kompleksa RTV.
Projekat sanacije osmišljen je u skladu sa novom namenom objekta, prema rezultatima procene stanja. Najoštećeniji elementi su uklonjeni i zamenjeni novim, uz dodatak čeličnog rama kao oslonca. Proračun je u svemu sproveden prema važećem pravilniku i standardima. Preseci AB ploče i rebara su usvojeni istih dimenzija kao i pre sanacije. Za poprečni presek grede čeličnog rama usvojen je IPBv 650 profil. Stubovi rama su usvojeni preseka IPB320.

Temeljna konstrukcija ispod stubova rama usvojena je dimenzija 3,5x2,5x0,5 m.

Dva objekta studija povezaće se Svodom od Leksan ploča, po dužoj strani. Ostale strane biće ukopane u zemlju, a na međuspratnoj ploči predviđen je intenzivni zeleni krov.

Akustična obloga za novoprojektovane prostorije studija birana je u odnosu na stroge zahteve u pogledu akustike studija, prema Elaboratu prostorne akustike.

\section{LITERATURA}

[1] M. Mijić "Građevinska akustika"

[2] D. Šumarac-Pavlović, M.Mijić, "Elektroakustika”, Beograd, ETF Beograd, 2017.

[3] M. Long - "Architectural Acoustics”, Elsevier, 2006

[4] M. Malešev, V. Radonjanin - Sanacija betonskih konstrukcija - predavanja

\section{Kratka biografija:}

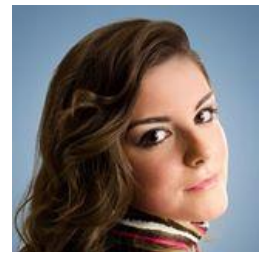

Olivera Bukvić rođena je u Novom Sadu 1993. god. Master rad na Fakultetu tehničkih nauka iz oblasti Građevinarstva - Procena stanja i sanacija betonskih konstrukcija odbranila je 2018.god.

kontakt: olivera.bukvic@uns.ac.rs 